\title{
Stress as a meaningful variable in models of
}

\section{covid-19 spreading}

Carlos Trenado ${ }^{1,2}$, Mauricio Santillana ${ }^{3,4}$, Diane Ruge ${ }^{5}$

${ }^{1}$ Institute of Clinical Neuroscience and Medical Psychology, Medical Faculty, Heinrich Heine University, Duesseldorf, Germany

${ }^{2}$ Systems Neuroscience and Neurotechnology Unit, Faculty of Medicine, Saarland University and HTW Saarland, Homburg/Saar, Germany

${ }^{3}$ Computational Health Informatics Program, Boston Children's Hospital

${ }^{4}$ Department of Pediatrics, Harvard Medical School

${ }^{5}$ UCL-Institute of Neurology, University College London (UCL), Queen Square, London WC1N $3 \mathrm{BG}, \mathrm{UK}$

\section{Correspondence to:}

Carlos Trenado, Institute of Clinical Neuroscience and Medical Psychology, Medical faculty, Heinrich Heine University, Moorenstr. 5, 40225 Düsseldorf, Germany

e-mail: carlos.trenadoc@gmail.com

Diane Ruge, UCL-Institute of Neurology, University College London (UCL), Queen Square, London WC1N 3BG, UK

e-mail: diane.ruge@gmail.com

Running title: use of the variable stress in models of covid-19 
Keywords: stress; covid-19; corona virus; multiscale; microscale; macroscale; stressor, stress models

Author Contributions: conceptualization: CT, DR

Author Contributions: investigation: CT, DR, MS

Author Contributions: methodology: CT, DR, MS

Author Contributions: writing (original draft preparation): CT, DR

Author Contributions: writing (review and editing): CT, DR, MS

Acknowledgments: The Dorothy Feiss Scientific Research Grant.

Competing interests: The authors declare that no competing interests exist. 
Covid-19 is a respiratory disease caused by the severe acute respiratory syndrome coronavirus -2 (SARS-CoV-2), which was first identified in Wuhan China in December 2019 (Huang C et al 2020). Because of Covid-19 worldwide spreading in the year 2020, urgent hygiene and lockdown measures have been implemented with fundamental consequences on the lives of people in all sectors of society. Stress is known to be either positive or negative. The consequences of stress can change with time of exposure. What turns out to be stressful for an individual is highly individual. Besides visible socio-economic and documented health effects, the impact of Covid-19 on people's mental health including stress-related effects on disease spreading is yet to be understood. Nevertheless, some stress-related factors that have been identified include: (1) fears of infection, (2) fears of a long-term economic crisis, (3) xenophobia, (4) compulsive checking and reassurance seeking, (5) traumatic stress about Covid-19 symptoms, (6) social isolation due to lockdown measures, (7) fears about getting false information from social media and conspiracy theories, (8) latent concerns about resurgence of disease after removal of lockdown measures (Wissmath et al 2020; Taylor et al. 2020). On the one hand, it has been reported that positive thinking and perceived social, organizational, and governmental support have been useful to mitigate worries and stress caused by Covid-19 (Wissmath et al 2020). In addition, lockdown measures have partly been positively evaluated as an opportunity to perform leisure activities, supporting the perception of "being in good health" (Rodríguez-Rey et al 2020). On the other hand, the socioeconomic crisis triggered by Covid-19 in the form of unemployment, social conflicts, exacerbated health-care systems, lockdown measures without ensuring people's basic needs, remains a source of stress and anxiety with prospective long-term consequences on mental health (Shammi et al. 2020, Rodríguez-Rey et al 2020).

To understand the impact of Covid-19 on people's mental state, subjective measures of stress have been gathered worldwide mostly by means of remote internet technologies (websites, email, mobile applications). While such measures point toward moderate to severe effect of Covid-19 on people's stress response (Rodriguez-Rey 2020), the effect of such response on disease propagation remains 
to be properly addressed. This observation is particularly accentuated by considering that brief or chronic stressors have potential to alter cellular and humoral immunity and thereby influence disease spreading (Segerstrom and Miller 2004). Thus, an important question that arises is at what level of detail should models of Covid-19 take stress factors into consideration?

At the macroscale level, subjective stress-related information has been emphasized in assessing people's mental health and supporting development of models that incorporate the effect of behavioral factors on disease spreading (Bavel et al. 2020). However, it is important to note that subjective reports of stress have been shown to be neither associated with changes in the immune system nor physiological measures of stress possibly due to methodological bias or asynchronicity of their temporal changes (Weckesser LJ et al. 2019). Nevertheless, well-known epidemiology (macroscale) models have been able to provide valuable information on disease spreading by considering stress-affecting factors, e.g. lockdown and hygiene measures such as the use of masks in public places. For instance, simulations based on SEIR and SEIQR models that incorporated such factors demonstrated a decrease in the number of Covid-19 infections thus principally providing support for the implementation of such non-pharmaceutical interventions and policies (German et al. 2020; Ibarra-Vega D, 2020; Li Y et al, 2020, Lai S et al. 2020). Here, it is important to note that in these models, varying the degree of contact among agents, accounted for the mentioned factors. However, neither the degree to which behavioral patterns of individual agents (microscale level) are modified by levels of anxiety and stress under current environmental conditions nor the physiological effects on the immune system of agents resulting from Covid-19 related stress were considered in these efforts explicitly. In other words, such models have overlooked the fact that covid-19 stress-related factors and the disease itself have short and long-term effects on mental health and the crucial observation that individuals react differently to such adverse environmental conditions, for instance some individuals feel release of being isolated from others potentially infected, while others suffer from social isolation and a sense of lack of freedom. In order to account for effects that occur at individual level but that have implications at the population level, 
we advocate the use of a multiscale modeling framework. Multiscale modeling uses multiple models at different scales simultaneously to describe a system, thus it should be able to consider physiological variables underlying Covid-19 effects on stress and immune system responses at the individual level so that they can be incorporated into a population dynamics model guided by behavioral patterns. Information gathered through such models, could not only play an important role in determining more accurate patterns of disease spreading by considering the mental state of agents, but also provide deeper insight into what human behavioral patterns would be more effective in controlling spreading of the pandemic. This observation becomes more relevant by considering that changes in social patterns (easing lockdown) potentially influence the resurgence of new infections. In relation to this, recent studies have shown that even in scenarios where specific communities reached an acceptable infection rate (effective reproductive number, $\mathrm{R}<1$ ) locally in time, a small variation in $\mathrm{R}$, resulting from easing lockdown measures, could lead to a significant impact on expected infection cases and deaths (Ziauddeen et al 2020). Recent studies have also shown that there is a super-linear scaling between percent contact reduction and required duration of application to have a lower number of fatalities, which holds true for an effective reproduction of $\mathrm{R}>1$ and is reverted for $\mathrm{R}<1$ (Neuwirth et al. 2020).

To consider the effect of stress-related factors into models of Covid-19 spread, a selection of the appropriate model(s) of stress, adjusted to a specified level of detail, will be necessary. For this, it is useful to emphasize that theoretical models of stress are differentiated by the degree in which they consider psychological and physiological responses resulting from adverse environmental conditions as well as the positive and/or negative consequences associated with such responses (See Table 1). As emphasized before, subjective perception towards Covid-19 stress-related factors varies among individuals and so their mental state as well as immune capabilities to cope with stress-related factors. By considering that subjective perception towards a threat is also delineated by socio-demographic, economic and cultural factors, the need to develop models that are customized to population characteristics or regions would be relevant when adopting a particular 
model of stress in relation to disease spreading in different populations. There are certain agents that have reduced stress and increased well-being under lock-down conditions. Since availability of physiological data is currently limited due to human-contact restrictions dictated by hygiene and lockdown policies, promising efforts to gather physiological data and thereby support development of multiscale models targeting effects of stress on disease spreading include the use of non-contact surveillance methods which could provide an estimate of indirect physiological markers of stress such as eye blink rates, breathing patterns and humoral factors. Ultimately, altruistic efforts of people around the world who are willing to share data to speed up worldwide assessment of stress-related factors caused by Covid-19 would be crucial to develop multiscale predictive models of its long-term effect on mental health.

Insert Table 1 here

\section{References}

Huang C, Wang Y, Li X, et al. Clinical features of patients infected with 2019 novel coronavirus in Wuhan, China. Lancet 2020;395(10223):497-506

Wissmath B, Mast FW, Kraus F, Weibel D. Understanding the psychological impact of the COVID-19 pandemic and containment measures: an empirical model of stress. MedRxiv 2020.05.13.20100313; doi: https://doi.org/10.1101/2020.05.13.20100313

Taylor S, Landry CA, Paluszek MM, Fergus TA, McKay D, Asmundson GJG. (2020). Development and initial validation of the COVID Stress Scales. J. Anxiety Dis., 72:102232, https://doi.org/10.1016/j.janxdis.2020.102232.

Rodríguez-Rey R, Garrido-Hernansaiz H and Collado S (2020) Psychological Impact and Associated Factors During the Initial Stage of the Coronavirus (COVID-19) Pandemic Among the General Population in Spain. Front. Psychol. 11:1540. doi: 10.3389/fpsyg.2020.01540

Shammi M, Bodrud-Doza M, Towfiqul Islam ARM, Rahman MM. COVID-19 pandemic, socioeconomic crisis and human stress in resource-limited settings: A case from Bangladesh. Heliyon. 2020 May;6(5):e04063. doi: 10.1016/j.heliyon.2020.e04063.

Segerstrom, S. C., \& Miller, G. E. (2004). Psychological stress and the human immune system: a meta-analytic study of 30 years of inquiry. Psychological bulletin, 130(4), 601-630. https://doi.org/10.1037/0033-2909.130.4.601 
Bavel, J.J.V., Baicker, K., Boggio, P.S. et al. Using social and behavioural science to support COVID-19 pandemic response. Nat Hum Behav 4, 460-471 (2020). https://doi.org/10.1038/s41562-020-0884-z

Weckesser, L.J., Dietz, F., Schmidt, K. et al. (2019) The psychometric properties and temporal dynamics of subjective stress, retrospectively assessed by different informants and questionnaires, and hair cortisol concentrations. Sci Rep 9, 1098. https://doi.org/10.1038/s41598-018-37526-2

German, R., Djanatliev, A., Maile, L., Bazan, P., Hackstein, H. (2020) Modeling Exit Strategies from COVID-19 Lockdown with a Focus on Antibody Tests. medRxiv 2020.04.14.20063750; doi: https://doi.org/10.1101/2020.04.14.20063750

Ibarra-Vega, D. (2020). Lockdown, one, two, none, or smart. Modeling containing covid-19 infection. A conceptual model, Sci. Total Environ., 730:138917

Li, Y., Wu, Y., Wang, X., Guo, C., Wang, L., Li, J., Wang, S. (2020) Modelling the effect of lockdown on COVID-19 pandemic in 22 countries and cities. doi: 10.21203/rs.3.rs-32891/v1

Lai, S., Ruktanonchai, N.W., Zhou, L. et al. Effect of non-pharmaceutical interventions to contain COVID-19 in China. Nature 585, 410-413 (2020). https://doi.org/10.1038/s41586-020-2293-x

Ziauddeen H., Subramanian, N; Gurdasani D. (2020) Modelling the impact of lockdown easing measures on cumulative COVID-19 cases and deaths in England. medRxiv preprint doi: https://doi.org/10.1101/2020.06.21.20136853.

Neuwirth, C., Gruber, C. and Murphy, T. Investigating duration and intensity of Covid-19 social-distancing strategies. Sci Rep 10, 20042 (2020).

\section{Legends}

Table 1. Different models of stress response that could be incorporated into models of Covid-19 disease spreading. Multiscale level encompasses micro and macro scale levels. 


\begin{tabular}{|c|c|c|c|}
\hline Model & Characteristic & $\begin{array}{l}\text { Effect of } \\
\text { Response } \\
\end{array}$ & $\begin{array}{c}\text { Modeling } \\
\text { Level }\end{array}$ \\
\hline Cannon & $\begin{array}{l}\text { Stress is a survival response that } \\
\text { promotes homeostatic restoration. }\end{array}$ & Negative & Microscale \\
\hline $\begin{array}{c}\text { Selye } \\
(\text { General } \\
\text { Adaptation } \\
\text { Syndrome (GAS)) }\end{array}$ & $\begin{array}{l}\text { Focuses on emotional and } \\
\text { physiological responses. It } \\
\text { involves three stages: alarm, } \\
\text { resistance, and exhaustion. }\end{array}$ & Positive/Negative & Multiscale \\
\hline $\begin{array}{l}\text { Perception, } \\
\text { cognition and } \\
\text { psychological } \\
\text { appraisal. }\end{array}$ & $\begin{array}{l}\text { Focuses on cognitive appraisal } \\
\text { of a stressful situation and the } \\
\text { mediating role of psychological } \\
\text { processes between environmental } \\
\text { events and organism's response. } \\
\text { Appraisal involves three stages: } \\
\text { primary, secondary and } \\
\text { re-appraisal. }\end{array}$ & Positive/Negative & Macroscale \\
\hline $\begin{array}{l}\text { Conservation of } \\
\text { resources }\end{array}$ & $\begin{array}{l}\text { Individuals strive to retain, } \\
\text { protect, and build valued } \\
\text { resources. Under no stress, } \\
\text { individuals develop resource } \\
\text { surpluses in order to offset the } \\
\text { possibility of future loss. }\end{array}$ & Positive/Negative & Multiscale \\
\hline Psychobiology & $\begin{array}{l}\text { Psychological and physiological } \\
\text { mechanisms are activated under } \\
\text { threat. Physiological markers of } \\
\text { stress include: heart rate, blood } \\
\text { flow, muscles urine, cortisol, } \\
\text { catecholamines. }\end{array}$ & Positive/Negative & Multiscale \\
\hline $\begin{array}{l}\text { Data driven } \\
\text { (Empirical) }\end{array}$ & $\begin{array}{l}\text { Addresses hidden relationships in } \\
\text { data through machine learning } \\
\text { and statistical methods. }\end{array}$ & Positive/Negative & Multiscale \\
\hline
\end{tabular}

Table 1 